\title{
Perivascular infiltration in normal skin of patients with rheumatoid arthritis: association with rheumatoid factors and HLA-DR antigens
} H J BERNELOT MOENS, ${ }^{1} \mathrm{H} \mathrm{J} \mathrm{W} \mathrm{AMENT,}^{1}$ Th M VROOM, ${ }^{2}$ T E W FELTKAMP,
AND J K VAN DER KORST

From the ${ }^{1}$ Jan van Breemen Institute, the ${ }^{2}$ Department of Pathology of the Slotervaart Hospital, and the $\overrightarrow{\vec{\omega}}$ ${ }^{3}$ Central Laboratory of the Netherlands Red Cross Blood Transfusion Service, Department of Autoimmune Diseases, Amsterdam, The Netherlands

SUMMARY The relation between immunohistological findings in biopsy specimens of apparentlyo normal skin, HLA antigens, and rheumatoid factors (RF) was studied in 120 patients with $\infty$ rheumatoid arthritis (RA), selected for treatment with D-penicillamine. Perivascular infiltration (PVI) of more than three mononuclear cells was present in $77(68 \%)$ of 114 patients, $\vec{\circ}$ accompanied usually by the presence of IgM or C3, or both, in immunofluorescence studies. Then number of perivascular cells was associated significantly with the titre of circulating RF. A weako relation of both perivascular cellular infiltration and RF with HLA-DR3 and DR4 did not reach ${ }^{\stackrel{\Phi}{ }}$ statistical significance. It is concluded that the histological presence of perivascular inflammati $2 \overrightarrow{0}$ is associated mainly with deposition of RF. It is suggested that the first is merely $0^{\circ}$ epiphenomenon of the latter. PVI was not prognostic for the occurrence of the clinicaialo syndrome of rheumatoid vasculitis. For practical purposes skin biopsies do not appear to bes useful in the evaluation of individual patients with RA.

Perivascular infiltrates of mononuclear cells, accompanied frequently by deposition of IgM or C3, or both, in immunofluorescence studies, are found in normal appearing skin of $25-65 \%$ of patients with rheumatoid arthritis (RA). ${ }^{1-6}$ In healthy controls and patients with osteoarthrosis such abnormalities are absent. ${ }^{357}$ The presence of these infiltrates has been associated with extra-articular disease manifestations, seropositivity, and circulating immune complexes, but does not necessarily indicate the clinical syndrome of rheumatoid vasculitis with skin ulcers, nail fold lesions, neuropathy, or gangrene. ${ }^{1-9}$

The importance of these findings is subject to discussion. Some regard it as an epiphenomenon, whereas others think they play a central part in the pathogenesis of RA. ${ }^{39} 10$ The genetic basis of RA has been demonstrated by the association with HLA-DR4 and also in twin studies. ${ }^{11} 12$ HLA-DR4 has been associated with manifestations of RA that indicate a more severe disease course: seropositiv-

Accepted for publication 29 February 1988.

Correspondence to Dr H J Bernelot Moens, Jan van Breemen Institute, Dr Jan van Breemenstraat 2, $1056 \mathrm{AB}$, Amsterdam, The Netherlands. ity, erosions, and extra-articular features like Felty'sō응 syndrome and rheumatoid vasculitis. ${ }^{12-21}$ Studies of ${ }^{3}$ a direct relation between HLA antigens and the presence of PVI have to our knowledge not been reported, though an association of PVI with HLA- $\frac{0}{2}$ DR4 has been mentioned. ${ }^{22}$

We took biopsy specimens of apparently normal skin from patients with RA who entered an open study of effectivity and toxicity of D-penicillamine. ${ }^{23}$ To evaluate possible associations with side effectso HLA typing was performed in most of these patients. These data enabled us to study the relationo between histological findings in normal skin, rheumatoid factors (RF), and HLA antigens-o subject of the present report.

\section{Patients and methods}

One hundred and twenty consecutive patients with? classical or definite RA, eligible for treatment with D-penicillamine, were studied. The male/female ratio was $45 / 75$, mean age 58 (range $24-80$ ) yearso and mean duration of disease 14 (range $1-44$ ) years. Eighty six patients $(72 \%)$ were seropositive (Rose- $\frac{?}{\mathbb{1}}$ 
Waaler test titre $\geqslant 1 / 16$ ), the others being seronegative on at least three occasions. Extra-articular features were present in seven patients: a combination of splenomegaly, episcleritis, and lymphadenopathy in one patient, episcleritis alone in two, and pleuritis with lymphadenopathy in one. Leg ulcers were present in two patients and a mild polyneuropathy in one. These patients did not have other manifestations of the clinical syndrome of rheumatoid vasculitis. Skin biopsy was performed in six of these seven patients.

Erythrocyte sedimentation rate (ESR), RF, and antinuclear factors (ANF) were measured with standard methods at the time the skin biopsy specimen was taken, i.e., before treatment with $D$ penicillamine was started. HLA typing with a standard microlymphocytoxicity assay was performed in the laboratory of the Blood Transfusion Service, University of Nijmegen (Dr P Reekers) and the central laboratory of the Netherlands Red Cross Blood Transfusion Service (Dr L P de Waal). As the decision to evaluate possible associations with tissue antigens was taken after the beginning of the study HLA-DR typing was not performed on 30 patients.

One hundred and fourteen patients consented to a skin biopsy. Punch biopsy specimens were taken from the medial side of the forearm. One specimen was snap frozen in liquid nitrogen for immunofluorescence studies, another was fixed in $4 \%$ formaldehyde and stained with haematoxylin and eosin (H\&E). The sections were initially assessed by the routine methods of the pathology department. Direct immunofluorescence was performed with monospecific rabbit antisera against IgG, IgM, IgA, $\mathrm{IgE}$, and $\mathrm{C} 3$. Immunoglobulins or $\mathrm{C} 3$, or both, were considered present when granular deposits in the subepidermal vessel walls exceeded the intensity of background staining. Previous studies in our laboratory of skin biopsy specimens from non-rheumatoid patients and a few patients who died from traffic accidents did not show deposition of $\mathrm{C} 3$, and rarely a slight deposition of IgM. ${ }^{24}$ To obtain an objective measure of perivascular infiltration all $\mathrm{H} \& \mathrm{E}$ sections were reassessed using a semiquantitative scale ranging from 0 to 3 as described by others. ${ }^{5}$ Less than three mononuclear cells per vessel were scored as 0 , with three to six cells the score was $1,7-10$ cells: 2, more than 10 cells: 3 . Skin biopsies, examinations of immunofluorescent sections, and the reassessment of $H \& E$ sections were performed by one of us (TMV).

Statistical analysis was performed with the $\chi^{2}$ test with Yates's correction.

\section{Results}

Characteristics of all patients, patients who had skin biopsies, and those who were HLA typed showed no important differences. Thus the probability of selection bias in these respects is small (Table 1).

Perivascular infiltration of more than three mononuclear cells was present in $77(68 \%)$ of 114 patients and of more than 10 cells in only two patients, both without clinical signs of vasculitis at the time of the biopsy. Immunofluorescence studies showed deposition of IgM, almost invariably together with C3 in 58 (51\%) patients. Deposition of IgA was found in one patient. IgE, bound to mast cells, was seen in five patients. As expected the prevalence of HLA-DR4 was significantly higher than in healthy Dutch blood donors $(71 \% v 20 \%)$. This was not the case for HLA-DR3 (16\% v 23\%). Results of both HLA typing and a skin biopsy were available from 86 patients.

The number of perivascular cells was significantly increased in patients who also had deposition of IgM or C3, or both, men, seropositive patients, patients with rheumatoid nodules, and patients possessing HLA-DR3 (Table 2). PVI was also more prevalent in patients with ANF or HLA-DR4, but the level of statistical significance was not reached.

The prevalence of serological abnormalities and rheumatoid nodules was increased slightly in patients having either HLA-DR3 or HLA-DR4, but

Table 1 Characteristics of all patients consenting to a skin biopsy or HLA typing, or both

\begin{tabular}{|c|c|c|c|}
\hline Characteristic & All patients & Skin biopsy & HLA typed \\
\hline Number & 120 & 114 & 90 \\
\hline Women & $75(63)^{*}$ & $71(62)$ & $58(64)$ \\
\hline Mean age in years (SD; range) & $58(12 ; 24-80)$ & $58(12 ; 24-80)$ & $57(12 ; 24-77)$ \\
\hline Mean duration in years (SD; range) & $14(10 ; 1-44)$ & $13(10 ; 1-44)$ & $14(9 ; 1-44)$ \\
\hline Rheumatoid nodules & $38(32)$ & $35(31)$ & $28(31)$ \\
\hline Radiological erosions & $110(92)$ & $104(91)$ & $83(92)$ \\
\hline Mean ESR in $\mathrm{mm} / \mathrm{h}$ (SD; range) & $52(28 ; 6-130)$ & $53(27 ; 6-130)$ & $52(28 ; 6-130)$ \\
\hline Rose-Waaler test titre $\geqslant 1 / 16$ & $86(72)$ & $82(72)$ & $65(72)$ \\
\hline Antinuclear factors & $32(27)$ & $30(26)$ & $24(27)$ \\
\hline
\end{tabular}

*Values are Nos (\%). 
840 Bernelot Moens, Ament, Vroom, Feltkamp, van der Korst

Table 2 Characteristics of 114 patients divided into three groups according to semiquantitative scoring of perivascular mononuclear cells

\begin{tabular}{|c|c|c|c|}
\hline Characteristic & $0(0-2$ cells $)$ & 1 (3-6 cells) & $2 / 3(>6$ cells $)$ \\
\hline Number & $37(32) \dagger$ & $49(43)$ & $28(25)$ \\
\hline IgM/C3 deposition & $6(16)$ & $29(59)$ & $23(82)^{* *}$ \\
\hline Men & $11(30)$ & $17(35)$ & $15(54)^{*}$ \\
\hline Mean age (years) & 61 & 57 & 58 \\
\hline Mean duration (years) & 16 & 13 & 11 \\
\hline Rheumatoid nodules & $6(16)$ & $16(33)$ & $13(46)^{*}$ \\
\hline Other EAF $\ddagger$ & $1(3)$ & $4(8)$ & $1(4)$ \\
\hline Radiological erosions & $34(92)$ & $44(90)$ & $26(93)$ \\
\hline Mean ESR (mm/h) & 58 & 47 & 57 \\
\hline Rose-Waaler test titre $\geqslant 1 / 16$ & $23(62)$ & $32(65)$ & $27(96)^{* *}$ \\
\hline Antinuclear factors & $6(16)$ & $14(29)$ & $10(36)$ \\
\hline Number HLA typed & $30(81)$ & $35(71)$ & $21(75)$ \\
\hline HLA-DR4 positive & $20(67)$ & $23(66)$ & $17(81)$ \\
\hline HLA-DR3 positive & $1(3)$ & $8(23)$ & $5(24)^{*}$ \\
\hline
\end{tabular}

* **Significantly increased $\left({ }^{*} p<0 \cdot 05,{ }^{* *} p<0.01 ; \chi^{2}\right.$ test $)$ if compared with patients with $\leqslant 6$ cells.

$\dagger$ Values are Nos (\%).

‡EAF=extra-articular features: see text.

again differences did not reach statistical significance (Table 3 ).

To analyse further the relation of RF and perivascular inflammation as well as HLA-DR antigens patients were divided into groups according to the

Table 3 HLA-DR3 and HLA-DR4 and some disease parameters

\begin{tabular}{lllrrr}
\hline & No & $R F+$ & \multicolumn{1}{c}{ ANF+ } & Nodùles & Erosion \\
\hline DR4+ & 64 & $49(77)^{*}$ & $17(27)$ & $22(34)$ & $58(91)$ \\
DR4- & 26 & $16(62)$ & $7(27)$ & $6(23)$ & $25(96)$ \\
DR3+ & 14 & $12(86)$ & $6(43)$ & $4(29)$ & $13(93)$ \\
DR3- & 76 & $49(64)$ & $18(24)$ & $24(32)$ & $70(92)$ \\
\hline
\end{tabular}

${ }^{*}$ Values are Nos (\%).

Differences do not reach statistical significance.

Table 4 Relation between titre of the Rose-Waaler test at the time of the biopsy, semiquantitative scoring of perivascular infiltration, and deposition of IgM or C3, or both

\begin{tabular}{lcccccc}
\hline Rose-Waaler & No & $0-2$ Cells & $3-6$ Cells & $>6$ Cells & IgM/C3 \\
\hline Negative & 37 & $16(43) \dagger$ & $17(46)$ & $4(11)$ & $7(19)$ \\
$1 / 8-1 / 16$ & 11 & $5(45)$ & $4(36)$ & $2(18)$ & $5(45)$ \\
$1 / 32-1 / 64$ & 17 & $6(35)$ & $8(47)$ & $3(18)$ & $12(71)$ \\
$\geqslant 1 / 128$ & 49 & $10(20)$ & $20(41)$ & $19(39)$ & $34(69)$ \\
All patients & 114 & $37(32)$ & $49(43)$ & $28(25)$ & $58(51)$
\end{tabular}

If all patients with Rose-Waaler test titres $\leqslant 1 / 16$ are compared with those with titres $\geqslant 1 / 32$ significant differences are found for the number of perivascular cells $\left(\chi^{2}=8.2, p<0.02\right)$ and deposition of $\operatorname{IgM} / \mathrm{C} 3\left(\chi^{2}=24 \cdot 6, p<0.01\right)$.
Table 5 Relation between titre of the Rose-Waaler test at the time of biopsy and HLA-DR3 and HLA-DR4

\begin{tabular}{lccr}
\hline $\begin{array}{l}\text { Rose-Waaler } \\
\text { test titre }\end{array}$ & No & $D R 3+$ & $D R 4+$ \\
\hline Negative & 21 & $2(10)^{*}$ & $15(71)$ \\
$1 / 8-1 / 16$ & 13 & $0(0)$ & $8(62)$ \\
$1 / 32-1 / 64$ & 14 & $2(14)$ & $8(57)$ \\
$\geqslant 1 / 128$ & 42 & $10(24)$ & $33(79)$ \\
All patients & 90 & $14(16)$ & $64(71)$ \\
\hline
\end{tabular}

${ }^{*}$ Values are Nos (\%).

Differences do not reach statistical significance.

titre of RF as estimated at the time of biopsy (Tables: 4 and 5). Deposition of IgM or C3, or both, as well as PVI were significantly associated with high titres. of RF. HLA-DR3 and DR4 were somewhat more prevalent in patients with high titres of RF, but the difference did not reach statistical significance.

\section{Discussion}

Within the broad spectrum of RA, seropositive disease with extra-articular features has been pro- $\widehat{N}$ posed as a separate disease entity. From many studies the clustering of RF, nodules, Felty'sN syndrome, and-less pronounced-radiological ${ }_{0}^{\omega}$ erosion of para-articular bone has become clear. This concept is further supported by the association? of these symptoms with HLA-DR4. It is likely thate PVI and deposition of IgM or C3, or both, are alsoassociated with this cluster. ${ }^{1-1}$ In this study PVI of mononuclear cells in normal skin was associated with seropositivity and the presence of rheumatoid 
nodules, confirming the above mentioned observations. A direct relation between extra-articular disease manifestations could not be shown as the latter were present in only six of 114 patients. Association of PVI with male sex (Table 2) is likely to be secondary to the association with RF and nodules, the latter being more often present in male patients with RA. Our data indicate a weak relation between ANF and HLA-DR3 as has been reported by others, both being weakly associated with PVI. ${ }^{15}{ }^{17}$ Perhaps these should also be regarded as markers for a more severe form of RA. PVI was present in $77 / 114(68 \%)$ of our patients with RA selected for treatment with D-penicillamine. Compared with other studies this figure is high, which may reflect partly rather serious and longstanding disease in our patients. More important are differences in the criteria that were used: a cut off point of six cells per vessel reduces the figure to $25 \%$.

The number of perivascular cells correlated with deposition of IgM or C3, or both, in the vessel wall, as reported in other studies. ${ }^{1-4}$ Both PVI and IgM/C3 deposition were associated with RF. The increasing number of perivascular cells in patients with high titres of RF (Table 4) can be regarded as an argument for a causal relation. Our data indicate a weak association of RF with HLA-DR3 and DR4 (Tables 3 and 5), not reaching statistical significance. As the connection between HLA-DR4 and $\mathrm{RF}$ is in agreement with observations of others ${ }^{13-17}$ we believe it is not likely to have resulted from chance. As higher titres of RF are associated with both PVI and HLA-DR4 an increased prevalence of this genetic marker in patients with dense infiltrates is expected. Although not reaching statistical significance, HLA-DR4 was indeed more frequently present in patients with infiltrates of more than six cells. HLA-DR3 also appears to be associated with PVI, but it is more correct to state that the prevalence of HLA-DR3 was in fact only decreased in patients with $0-3$ cells as the overall prevalence in the other groups did not exceed that in healthy controls.

From a pathogenetic point of view as well as from a practical one it is important to address the question of what comes first: RF or vasculitis? Intravenous administration of RF to rats is followed by diapedesis of leucocytes from venules and capillaries and may induce cutaneous inflammation. 2526 When this observation is extended to patients with RA one may propose a hypothesis of circulating (IgM) RF being trapped or deposited in the vessel wall, activating the complement system, and attracting leucocytes. ${ }^{3}$ The demonstration of IgM or C3, or both, in most patients with PVI (Table 2) is in agreement with this hypothesis but does not prove that deposition or formation of immune complexes in the vessel wall precedes cellular infiltration.

If HLA-DR4 is a marker for the genetic basis of a more severe disease process, including high titres of RF and PVI, one would expect a stronger association with the primary disease manifestation. Our finding that HLA-DR4 is more prevalent in patients with RF than in patients with perivascular inflammation supports the hypothesis that PVI is secondary to deposition of circulating RF.

In the management of patients with RA information on the presence of PVI will only be helpful if clear associations with certain disease manifestations or prognosis can be demonstrated. Westedt et al found correlation of PVI with active joint inflammation using the Ritchie index. ${ }^{4}{ }^{7}$ Disease activity in our patients, as measured by the ESR, was not associated with the presence or degree of perivascular inflammation. A possible prognostic significance of PVI has been evaluated in two studies. ${ }^{46}$ Neither PVI nor skin vessel wall immune deposits were predictive of change in activity of joint disease or development of extra-articular manifestations. In our patient group, after an average follow up period of $7(1-10)$ years, $2 / 86$ patients with $0-6$ perivascular cells, and $3 / 28$ patients with $>6$ cells had developed minor clinical signs of vasculitis: skin ulcers, combined with nail fold lesions in two. These five patients were all seropositive, two had ANF, while HLA-DR4 was present in 4/4 and HLA-DR3 in 0/4. In our opinion this outcome does not indicate a useful prognostic significance of skin biopsies.

In conclusion, perivascular cellular infiltration in apparently normal skin of patients with RA is associated with some of the symptoms that mark a more severe disease course. HLA-DR4 has also been associated with these symptoms, but its prevalence is only marginally increased in patients with perivascular inflammation. The perivascular infiltrates are probably secondary to the presence and quantity of circulating RF.

It is not likely that skin biopsies will provide a better insight into the prognosis of RA for individual patients. To identify patients with a more severe disease course or a high risk of developing extraarticular symptoms other tests like RF and ANF can be obtained more easily and are probably better discriminators.

\section{References}

1 Conn D L, Schroeter A L, McDuffie F C. Cutaneous vessel immune deposits in rheumatoid arthritis. Arthritis Rheum 1976; 19: $15-19$.

2 Rapoport R J, Kozin F, Mackel S E. Cutaneous vascular immunofluorescence in rheumatoid arthritis. Correlation with 
circulating immune complexes and vasculitis. Am J Med 1980; 68: $325-31$.

3 Nelson H M, MacKie R M. Studies in cutaneous immunofluorescence. Histological and direct immunofluorescence observations in clinically normal skin of patients with rheumatoid arthritis. J Cutan Pathol 1981; 8: 105-10.

4 Westedt M-L, Vermeer B J, Meijer C J L M, Daha M R, Baldwin W M III, Cats A. Immunopathological abnormalities in the normal skin of patients with rheumatoid arthritis in relation to clinical and serological findings: a one year follow up study. Ann Rheum Dis 1987; 46: 213-8.

5 McGill P E, Brougham P A, Tulloch J. Immune deposits in the skin of patients with rheumatoid arthritis. J Rheumatol 1984; 11: 454-6.

6 Mielke H, Daniel W, Deicher H, et al. A three-year prospective study of systemic manifestation in rheumatoid arthritis. Clin Rheumatol 1987; 6 (suppl 2): 26-34.

7 Westedt M L, Meijer C J L M, Vermeer B J, Cats A. Rheumatoid arthritis-the clinical significance of histo- and immunopathological abnormalities in normal skin. $J$ Rheumatol 1984; 11: 448-52.

8 Scott D G I, Bacon P A, Tribe C R. Systemic rheumatoid vasculitis: a clinical and laboratory study of 50 cases. Medicine (Baltimore) 1981; 60: 288-97.

9 Kulka J P. The vascular lesions associated with rheumatoid arthritis. Bull Rheum Dis 1959; 10: 201-2.

10 Rothschild B M, Masi A T. Pathogenesis of rheumatoid arthritis: a vascular hypothesis. Semin Arthritis Rheum 1982; 12: 11-31.

11 Calin A. The case against seronegative rheumatoid arthritis. Am J Med 1981; 70: 992-4.

12 Panayi G S, Wooley P, Batchelor J R. Genetic basis of rheumatoid disease: HLA antigens, disease manifestation, and toxic reactions to drugs. $\mathrm{Br}$ Med $J$ 1978; ii: 1326-8.

13 Westedt M L, Breedveld F C, Schreuder G M Th, D'Amaro J D, Cats A, de Vries R R P. Immunogenetic heterogeneity of rheumatoid arthritis. Ann Rheum Dis 1986; 45: 534-8.

14 Gran J T, Husby G, Thorsby E. HLA DR antigens in rheumatoid arthritis. Scand J Rheumatol 1983; 12: 241-5.

15 Griffin A J, Wooley P, Panayi G S, Batchelor J R. HLA DR antigens and disease expression in rheumatoid arthritis. $A n \underline{n}$ Rheum Dis 1984; 43: 218-21.

16 Walton K, Dyer P A, Grennan D M, Haeney M, Harris $R^{\frac{w}{2}}$ Clinical features, autoantibodies and HLA-DR antigens rheumatoid arthritis. J Rheumatol 1985; 12: 223-6.

17 Doblough J H, Forre O, Kass E, Thorsby E. HLA antigens an rheumatoid arthritis. Association between HLA-DRw4 positivo ity and IgM rheumatoid factor production. Arthritis Rheur 1980; 23: 309-12.

18 Emery P, Panayi G S, Welsh K I, Cole B C. Rheumatoi factors and HLA-DR4 in RA. $J$ Rheumatol 1985; 12: 217-2240

19 Young A, Jaraquemada D, Awad J, et al. Association of HLA-DR4/Dw4 and DR2/Dw2 with radiologic changes in $₫$ prospective study of patients with rheumatoid arthritis. Arthritis Rheum 1984: 27: 20-5.

20 Dinant H J, Hissink Muller W, van den Berg-Loonen E MR Nijenhuis L E, Engelfriet C P. HLA-DRw4 in Felty's syn drome. Arthritis Rheum 1980; 23: 1366.

21 Gran J T, Husby G. HLA antigens in palindromic rheumatism nonerosive rheumatoid arthritis and classical rheumatoid arthritis. J Rheumatol 1984; 11: 136-40.

22 Gonzalez T, Garcia-Montelongo R, Gantes M. Cutaneous microvasculopathy in rheumatoid arthritis. $J$ Rheumatol $1989^{\circ}$ 12: $1206-7$.

23 Bernelot Moens H J, Ament H J W, Feltkamp T E W, et al Longterm follow-up of treatment with D-penicillamine fot rheumatoid arthritis: effectivity and toxicity in relation to HLA antigens. $J$ Rheumatol 1987; 14: 1115-9.

24 Feltkamp-Vroom T M, Stallman P J, Aalberse R C, et a邑 Immunofluorescence studies on renal tissue, tonsils, adenoids, nasal polyps, and skin of atopic and non-atopic patients, \&itte special reference to IgE. Clin Immunol Immunopathol 197\$ 40 392-404.

25 Baum J, Stasny P, Ziff M. Effects of the rheumatoid factorong antigen antibody complexes on the vessels of the rat mesentery J Immunol 1964; 93: 985-92.

26 Floyd $\mathrm{M}$, Tesar J T. The role of IgM rheumatoid factor if experimental immune vasculitis. Clin Exp Immunol 1979; 36p 165-74. 